cc) (i) (2)

\title{
Formação de professores na perspectiva da complexidade: um estado da arte
}

\author{
Priscila Moreira Silva de Farias \\ Universidade Federal de São Carlos - UFSCar, Brasil \\ Rosa Aparecida Pinheiro \\ Universidade Federal de São Carlos - UFSCar, Brasil
}

\section{RESUMO}

Neste tempo de incerteza, pensar a Formação de Professores a partir de um contexto mais amplo é urgente. Para tal, conhecermos o já produzido no campo de Formação de Professores na ótica da Complexidade é a pretensão desta investigação, que apresenta um estado da arte sobre o assunto, no período de 2000 a 2018. O texto considerou as dissertações e teses cadastradas no Google Acadêmico e na Biblioteca Digital de Teses e Dissertações com os descritores "paradigma da Complexidade na Formação de Professores" e "Formação de Professores na perspectiva da Complexidade". Foram encontrados e analisados 20 trabalhos e após a leitura completa dos textos, a análise contemplou contextos nos quais as pesquisas foram desenvolvidas, os objetivos, os sujeitos das investigações, metodologias adotadas e resultados alcançados. Os achados indicam que há estudos consolidados sobre o tema e apontam a complexidade como possibilidade à Formação de Professores na e para a contemporaneidade.

PALAVRAS-CHAVE: Estado da Arte. Complexidade. Formação.

\section{TEACHER TRAINING FROM THE PERSPECTIVE OF COMPLEXITY: A STATE OF THE ART}

\begin{abstract}
In this time of uncertainty, thinking about Teacher Education from a broader context is urgent. For such, knowing what has already been produced in the field of Teachers' Training from the perspective of Complexity is the aim of this investigation, which presents a state of the art on the subject, in the period from 2000 to 2018. The text considered the dissertations and theses registered in Google Academic and in the Digital Library of Theses and Dissertations with the descriptors "Complexity paradigm in Teachers' Training" and "Teachers' Training in the perspective of Complexity". Twenty works were found and analyzed and after the complete reading of the texts, the analysis contemplated the contexts in which researches were developed, the objectives, the subjects of the investigations, adopted methodologies and achieved results achieved. The findings indicate that there are consolidated studies on the subject and point to complexity as a possibility for Teacher Education in and for contemporaneity
\end{abstract}


KEYWORDS: State of the Art. Complexity. Training

\section{LA FORMACIÓN DEL PROFESORADO DESDE LA PERSPECTIVA DE LA COMPLEJIDAD: UN ESTADO DEL ARTE}

\section{RESUMEN}

En este momento de incertidumbre, es urgente pensar en la Formación Docente desde un contexto más amplio. Para ello, conocer lo que ya se ha producido en el campo de la Formación Docente desde la perspectiva de la Complejidad es el objetivo de esta investigación, que presenta un estado del arte sobre el tema, en el período 2000-2018. El texto consideró las disertaciones y tesis registradas en Google Académico y en la Biblioteca Digital de Tesis y Disertaciones con los descriptores "Paradigma de la complejidad en la formación del profesorado" y "Formación del profesorado en la perspectiva de la complejidad". Se encontraron y analizaron veinte trabajos y luego de la lectura completa de los textos, el análisis contempló los contextos donde se desarrollaron las investigaciones, los objetivos, los sujetos de las investigaciones, las metodologías adoptadas y los resultados obtenidos. Los hallazgos indican que existen estudios consolidados sobre el tema y apuntan a la complejidad como una posibilidad para la Formación Docente en y para la contemporaneidad.

PALABRAS CLAVE: Estado del arte. Complejidad. Formación.

\section{INTRODUÇÃO}

A trajetória histórica da humanidade é marcada por intensas transformações e com elas percebemos alterações e desfazimento de valores, questionamentos de certas análises, emergência de novas concepções de mundo, de homem, de conhecimento. Estas transformações repercutem em todas as áreas, atingem a Educação e, consequentemente, o campo de Formação de Professores - o que nos conduz à necessidade de um repensar contínuo sobre o cenário educacional, uma vez que não é possível conceber a educação, a escola e o professor às margens de tais mudanças.

O repensar da Formação de Professores compreende olhar para os paradigmas científicos que a sustenta, pois estes instituem modelos, padrões que orientam as relações sociais, produzem posturas e podem ser entendidos como um conjunto de crenças que subsidia o nosso modo de pensar e operar em um determinado momento histórico. Pensar sobre eles pressupõe pensar, primeiramente, de maneira plural, já que não existe um único paradigma, depois, de maneira singular, entendendo que cada um dos paradigmas científicos possui suas próprias especificidades e por fim, pensar em suas diversidades, entendendo diversidade como diferentes elementos reunidos no mesmo paradigma. 
Em nosso tempo atual, embora estejamos diante de grandes transformações sociais, iniciamos o século XXI ainda sob forte influência dos paradigmas dos séculos XIX e XX, tendo o método cartesiano como forma de organizar o pensamento, de acordo com Behrens (2011). A visão que se disseminou como o "paradigma cartesiano-newtoniano", em homenagem aos precursores Rene Descartes e Newton, não surgiu de um novo método científico criado por estes idealizadores.

Esse paradigma, também conhecido como conservador ou dominante foi resultado de um longo processo de evolução de diversas ciências, no decorrer de alguns séculos. Ele trouxe, enquanto características indiscutíveis, o princípio de causalidade, a certeza, a objetividade e a fragmentação de pensamento. Neste contexto social, a Educação, assim como as demais áreas do conhecimento, não se furtou das influências do pensamento newtoniano/ cartesiano e suas contribuições foram (e são) tão profundas que a educação atual ainda se serve desse modelo.

Ao refletir sobre essa constatação, conclui-se que uma visão fragmentada, simplificadora e linear nos impossibilita de reconhecer as possibilidades de conexões que poderiam favorecer o atendimento das demandas apresentadas no cotidiano dos processos educativos. E pensando na Formação de Professores, que na atualidade também se alicerça em um paradigma que fragmenta e separa e que, portanto, precisa ser superado, é que esse trabalho se constrói

Na contemporaneidade uma possibilidade se apresenta como frutífera à superação dessa lógica e à Formação de Professores: trata-se da Complexidade. Mas, para que proposições e mudanças se efetivem neste campo é preciso inicialmente conhecer o que já foi construído pelas pesquisas como contribuição para os fundamentos e procedimentos formativos. Nesta direção, propomos este estudo que tem como objetivo apresentar o estado da arte das pesquisas que vinculam o campo de Formação de Professores e a Complexidade.

Esse tipo de pesquisa se faz importante porque favorece conhecer (para inferir) sobre o que tem sido produzido ao longo dos anos em uma determinada área do conhecimento, pois segundo Romanowski e Ens (2006, p.38), é possível dizer “que faltam estudos que realizem um balanço e encaminhem para a necessidade de um mapeamento que desvende e examine o conhecimento já elaborado [...]”. A realização de mais estudos nessa modalidade pode contribuir para que muitas produções acadêmicas não se percam.

Para o levantamento das produções acadêmicas que tratam da temática, realizou-se uma pesquisa no primeiro semestre de 2019, com o primeiro critério estabelecido de buscar dissertações e teses publicadas entre os anos de 2000 a 2018. Elegemos como base de dados o Google Acadêmico (https://scholar.google.com.br/) e a BDTD - Biblioteca Digital de Teses e 
Dissertações (http://bdtd.ibict.br/) considerando os descritores "paradigma da Complexidade na Formação de Professores "e "Formação de Professores na perspectiva da Complexidade".

No Google Acadêmico, o descritor "paradigma da Complexidade na formação de professores" apresentou 159.000 resultados. Ao selecionar as páginas em português e inserir o recorte temporal de 2000 a 2018, o número reduziu para 24.400 e, com o segundo descritor "formação de professores na perspectiva da Complexidade", o resultado foi de 310.000 trabalhos.

A respeito da busca nessa base de dados, cabe ressaltar que ao usar os descritores escolhidos, todas as palavras neles contidas foram consideradas, isto é, todos os trabalhos que continham qualquer uma das palavras dos descritores vieram como resultados. Diante das produções que emergiram, verificaram-se os títulos dos trabalhos e uma vez observada alguma relação com a presente pesquisa, foram feitas as leituras dos resumos, introduções e capítulos sobre a Complexidade conferindo se traziam a concepção a partir de Morin. O resultado usando o primeiro descritor reverberou em 1 tese e com o segundo descritor, o resultado foi de 6 trabalhos: 5 teses e 1 dissertação.

Já na BDTD - Biblioteca Digital de Teses e Dissertações, o descritor "paradigma da Complexidade na formação de professores" trouxe como resultado 131 produções, sendo 82 dissertações e 49 teses. Com os mesmos procedimentos adotados na seleção dos trabalhos na base de dados do Google Acadêmico, realizou-se a leitura dos títulos, dos resumos, introduções e dos capítulos que tratavam da Complexidade e os resultados foram 13 trabalhos: 10 teses e 3 dissertações. Com o descritor "formação de professores na perspectiva da Complexidade", a busca identificou 5 produções: todas repetidas, portanto excluídas do rol. Ao total, foram encontrados e analisados 20 trabalhos, sendo 4 dissertações e 16 teses.

No que diz respeito à análise dos trabalhos, esta se deu a partir da leitura completa dos textos, pois quando a intenção do pesquisador é inventariar produções acadêmicas para identificar as tendências, potencialidades, fragilidades, escolhas teóricas e metodológicas, estabelecendo aproximações e fronteiras entre os trabalhos, em uma determinada área do conhecimento, a leitura apenas dos resumos ou de alguns capítulos não dão conta de trazer a totalidade do estudo. Ler os trabalhos na íntegra propiciou referenciais mais consistentes para conduzir as análises, contemplando as instituições onde as pesquisas foram desenvolvidas, seus objetivos, os sujeitos das investigações, as metodologias adotadas pelos pesquisadores e os principais resultados alcançados. O material que aqui apresentamos se configura como um trabalho de caráter exploratório, uma vez que permitirá uma maior familiaridade entre as pesquisadoras e o tema investigado. 


\section{A COMPLEXIDADE NA FORMAÇÃO DE PROFESSORES: COMPREENDENDO ESTA RELAÇÃO A PARTIR DE UM MAPEAMENTO DE TESES E DISSERTAÇÕES}

A Complexidade traz em seu bojo a concepção de conjunto, de junção, de universo, de multidimensionalidade, a noção de que tudo está ligado a tudo, que tudo é influenciado por tudo. Uma ideia de intercruzamento, de entrelaçamento. Aprofundando a discussão em Morin (2003, p.43), sob o aspecto epistemológico, a palavra Complexidade:

[...] provém de complectere, cuja raiz plectere significa trançar, enlaçar. Remete ao trabalho da construção de cestas, unindo o princípio com o final de pequenos ramos. A presença do prefixo "com" acrescenta o sentido da dualidade de dois elementos opostos que se entrelaçam intimamente, mas sem anular a dualidade. Por isso a palavra complectere é utilizada tanto para designar o combate entre dois guerreiros, como o abraço apertado de dois amantes.

Essa perspectiva percebe o mundo como uma interligação das partes. Busca a superação da lógica linear que separa e exclui dimensões de um fenômeno, na tentativa de compreendêlo. Em lugar da certeza cartesiana, da linearidade, causa-efeito, do determinismo e visão estrutural, os processos auto-organizadores se constituem em um movimento dinâmico, com certo grau de incerteza e em um universo de probabilidades. O pensamento é em rede e o conhecimento não é mais fixo, e sim aproximado.

$\mathrm{Na}$ Complexidade o que está em relevo não são os resultados prontos e acabados, mas sim, os processos. Isso significa dizer que o conhecimento não é algo a ser enxertado no ser humano, mas uma construção contínua, individual e coletiva.

É uma visão que não se apresenta como receita ou como resposta, mas como um desafio e como motivação para pensar. Surge como incerteza, não priorizando os fragmentos, segundo a alternativa do reducionismo - que propõe conhecer o todo partindo somente das partes, tão pouco considerando o holismo - que negligencia as partes para compreender o todo. É uma visão que não pode ser vista como inimiga da ordem e da clareza e ao mesmo tempo não se confunde com a completude.

Para a Educação, este paradigma propõe uma visão crítica, reflexiva e transformadora, exigindo a interconexão de múltiplas abordagens e abrangências, apresentando para a Formação de Professores como possibilidade que dialoga com as necessidades da e para a contemporaneidade. Nesta ótica, nosso olhar se volta para buscar a relação entre a Formação de Professores e a Complexidade com a intenção de colocar em relevo as potencialidades que essa concepção traz ao campo de formação docente. No que concerne a problemática do estudo, nos ocupamos em saber: o que as produções acadêmicas revelam sobre a Formação de 
Professores na perspectiva da Complexidade? Em quais contextos estas produções foram desenvolvidas? O que tomam como sujeitos de investigação? Quais escolhas metodológicas e quais resultados apresentam?

Uma vez encontradas as pesquisas cadastradas no Google Acadêmico e na BDTD que tratam da temática, o corpus de análise deste trabalho se constituiu das seguintes produções: Possolli (2009); Wadt (2009); Carpim (2011); Fialho (2011); Rabelo (2011); klammer (2011); Batista (2012); D’Espósito (2012); Malosso Filho (2012); Dornelles (2013); Maissiat (2013); Pitombeira (2013); Saheb (2013); Gomes (2014); Lopes (2015); Souza (2015); Aguiar (2016); Pereira (2017); Priuli (2017) e Burian (2018).

A pesquisa é composta por $80 \%$ de teses e $20 \%$ de dissertações e a primeira descoberta diz respeito à concentração de produções acadêmicas desenvolvidas em instituições privadas do país (70\% das produções). No que concerne à distribuição por regiões brasileiras, os dados revelaram que a região Sudeste do Brasil é a que possui maior número de trabalhos no período investigado, seguida da região Sul.

Quadro 1 - Produções por Instituições

\begin{tabular}{|c|c|c|c|c|c|}
\hline \multicolumn{2}{|c|}{ INSTITUIÇÕES } & \multirow{2}{*}{$\begin{array}{c}\text { QTD. } \\
1\end{array}$} & \multicolumn{2}{|r|}{ INSTITUIÇÕES } & QTD. \\
\hline \multirow{9}{*}{ Dissertação } & $\begin{array}{l}\text { Pontifícia Universidade } \\
\text { Católica de São Paulo }\end{array}$ & & \multirow{9}{*}{ Tese } & $\begin{array}{l}\text { Universidade Estadual } \\
\text { Paulista }\end{array}$ & 1 \\
\hline & $\begin{array}{l}\text { Pontifícia Universidade } \\
\text { Católica do Paraná }\end{array}$ & 2 & & $\begin{array}{l}\text { Universidade Católica de } \\
\text { Pelotas }\end{array}$ & 1 \\
\hline & $\begin{array}{l}\text { Universidade Federal } \\
\text { Rural de Pernambuco }\end{array}$ & 1 & & $\begin{array}{l}\text { Pontifícia Universidade } \\
\text { Católica de São Paulo }\end{array}$ & 6 \\
\hline & & & & $\begin{array}{l}\text { Pontifícia Universidade } \\
\text { Católica do Rio Grande do }\end{array}$ & 1 \\
\hline & & & & $\begin{array}{l}\text { Universidade Federal do } \\
\text { Paraná }\end{array}$ & 2 \\
\hline & & & & $\begin{array}{l}\text { Universidade Federal do Rio } \\
\text { Grande do Sul }\end{array}$ & 1 \\
\hline & & & & $\begin{array}{l}\text { Universidade Federal de } \\
\text { Minas Gerais }\end{array}$ & 1 \\
\hline & & & & $\begin{array}{l}\text { Universidade Federal Rural } \\
\text { de Pernambuco }\end{array}$ & 2 \\
\hline & & & & Universidade Nove de Julho & 1 \\
\hline
\end{tabular}

Fonte: as autoras

Percebemos que a Educação não é a única área a tomar a temática como objeto de estudo, pois por ser um paradigma que integra e correlaciona, outros programas de Pós- 
Graduação como Linguística Aplicada e Estudos da Linguagem, Ciências e Informática também pesquisam o tema.

Quadro 2 - Trabalhos distribuídos por Programas de Pós-graduação

\begin{tabular}{|l|c|}
\hline \multicolumn{1}{|c|}{ PESQUISA } & PROGRAMAS DE PÓS-GRADUAÇÃo \\
\hline $\begin{array}{l}\text { (WADT, 2009); (FIALHO, 2011); (BATISTA, 2012); } \\
\text { (D’ESPOSITO, 2012); (PITOMBEIRA, 2013); } \\
\text { (GOMES, 2014); (AGUIAR, 2016); (PRIULI, 2017); } \\
\text { (BURIAN, 2018) }\end{array}$ & $\begin{array}{c}\text { Linguística Aplicada e Estudos da } \\
\text { Linguagem }\end{array}$ \\
\hline $\begin{array}{l}\text { (POSSOLLI, 2009); (CARPIM, 2011); (RABELO, } \\
\text { 2011); (KLAMMER, 2011); (MALOSSO FILHO; } \\
\text { 2012); (DORNELLES, 2013); (SAHEB, 2013); } \\
\text { (PEREIRA, 2017) }\end{array}$ & Educação \\
\hline (MAISSIAT, 2013) & Informática da Educação \\
\hline & \multicolumn{1}{|c|}{ Ciências } \\
\hline
\end{tabular}

Fonte: as autoras

No que se refere aos objetivos das pesquisas, observamos uma pluralidade nas investigações. Para além dos objetivos que focalizam a formação inicial e a continuada, outros se apresentam: a investigação da prática pedagógica dos professores, os saberes mobilizados nos processos de formação, as concepções paradigmáticas, as crenças dos professores, a ampliação da compreensão das dimensões subjetivas, assim como a descrição e a interpretação de fenômenos da experiência humana.

O corpus analítico constatou que as pesquisas ocorrem em diferentes níveis de ensino, tais como nos anos finais do Ensino Fundamental, no Ensino Médio, no Ensino Superior, na Pós-Graduação em nível de Especialização e nas dimensões tecnológica e profissional. Quanto às escolhas metodológicas, observamos a predominância da pesquisa qualitativa. Dos 20 trabalhos analisados, somente Gomes (2014) apresentou uma pesquisa qualiquantitativa. Dentro da visão qualitativa, há destaque para a abordagem Hermenêutica Fenomenológica.

A relação entre os objetivos e os resultados também foi analisada de acordo com o que cada estudo tomou como foco de investigação. Apresentaremos a seguir as relações identificadas e o modo como os trabalhos puderam ser agrupados. 
Quadro 3 - Agrupamentos dos trabalhos de acordo com os principais objetivos elencados

\begin{tabular}{|c|c|}
\hline PESQUISA & SUJEITOS DA INVESTIGAÇÃO \\
\hline $\begin{array}{l}\text { (WADT, 2009); (FIALHO, 2011); (KLAMMER, } \\
\text { 2011); (BATISTA, 2012); (D'ESPÓSITO, 2012); } \\
\text { (MALOSSO FILHO, 2012); (MAISSIAT, 2013); } \\
\text { (LOPES,2015); (PEREIRA, 2017); (PRIULI, } \\
\text { 2017); (BURIAN, 2018) }\end{array}$ & $\begin{array}{l}\text { Pesquisas que tomam ferramentas } \\
\text { tecnológicas, teorias e cursos como } \\
\text { sujeitos de investigação para formar } \\
\text { professores. }\end{array}$ \\
\hline $\begin{array}{l}\text { (POSSOLLI, 2009); (CARPIM, 2011); (RABELO, } \\
\text { 2011); (DORNELLES, 2013); (PITOMBEIRA, } \\
2013) ; \quad \text { (SAHEB, 2013); (GOMES, 2014); } \\
\text { (SOUZA, 2015); (AGUIAR, 2016) }\end{array}$ & $\begin{array}{l}\text { Pesquisas que tomam os professores } \\
\text { como sujeitos de investigação para tratar } \\
\text { de sua formação. }\end{array}$ \\
\hline
\end{tabular}

Fonte: as autoras

No que diz respeito aos objetivos que compõem as pesquisas que tomam ferramentas tecnológicas, teorias e cursos como sujeitos de investigação para formar professores, temos:

a) Refletir sobre ações organizacionais, a partir da forma como elas podem aparecer nas páginas de entrada de um curso, e trazer à tona quais são os aspectos do curso nos quais o professor pode se apoiar para poder resolver problemas de imprevisibilidade, que serão expressos na Agenda (WADT, 2009);

b) Observar uma disciplina do Curso de Licenciatura em Letras Espanhol e Literaturas de Língua Espanhola a distância, da UAB/UFSM, e de que forma essa disciplina se constitui como um sistema complexo (FIALHO, 2011);

c) Investigar a contribuição de um programa de Lato Sensu, de formação continuada, de uma determinada universidade particular, da cidade de Curitiba, para a prática docente numa perspectiva do paradigma da Complexidade - que considera o uso das tecnologias da informação e comunicação numa visão crítica (KLAMMER, 2011);

d) Descrever e interpretar experiência de dois fenômenos da experiência humana: à elaboração-operacionalização de um curso online com base na Teoria da Complexidade (BATISTA, 2012);

e) Compreender a natureza de dois fenômenos da experiência humana: desenho e implementação de um curso a distância de prática escrita em língua inglesa, para professores do Ensino Médio da rede pública estadual, na cidade de São Paulo, sob a perspectiva da Complexidade (D’ESPÓSITO, 2012);

f) Analisar, a partir dos subsídios fornecidos pela Teoria da Complexidade, a Educação e a Formação do professor no atual modelo formativo (MALOSSO FILHO, 2012); 
g) Identificar como e quais são as ações necessárias, em um ambiente virtual de ensino e de aprendizagem para capacitar um professor de arte, entendendo-se que este habita em um universo complexo (MAISSIAT, 2013);

h) Analisar uma proposta de formação em serviço, para docentes universitários, utilizando o Modelo das Múltiplas Perspectivas (MoMuP) e os princípios da Aprendizagem Cooperativa visando propiciar a articulação dos saberes experienciais, do conteúdo e da prática pedagógica de docentes universitários através da autonomia construtivista (LOPES, 2015);

i) Identificar, caracterizar e descrever as teorias que fundamentam a formação em Educação Física no Brasil, para propor um olhar característico da Complexidade à formação dos futuros professores (PEREIRA, 2017);

j) Descrever e interpretar um fenômeno experiência humana compreendido como o processo de transposição, ou seja, uma adaptação da aula para videoaula na perspectiva dos professores de línguas em formação (PRIULI, 2017);

k) Descrever e interpretar o fenômeno a vivência de um curso online de Formação de Professores de inglês dos Anos Finais do Ensino Fundamental da rede pública do Estado de São Paulo, na perspectiva da Complexidade (BURIAN, 2018)

Nesse primeiro bloco observamos espaços diversificados das ações educativas, como disciplinas, cursos, programa de Lato Sensu de formação continuada, proposta de formação em serviço, curso online e ambiente virtual de ensino e de aprendizagem. Apresentam-se espaços já usuais nas pesquisas e outras que investem na EAD e nos Ambientes Virtuais de Aprendizagem para Formação de Professores. Essa ampliação pode se dar às facilidades proporcionadas pelo desenvolvimento tecnológico, o que faz com que a $\mathrm{EAD}$, mediada pelo uso do computador e internet, alcance novos ambientes. Os resultados dos estudos apontam um consenso de que a Complexidade pode favorecer a Formação de Professores e que a contemporaneidade convoca uma visão integradora.

O estudo desenvolvido por Malosso Filho (2012) indica que o pensamento complexo se coloca como uma alternativa para reconfiguração do modelo social contemporâneo e de novas alternativas, e que este, embora originado no paradigma cartesiano, está cada vez mais se aproximando do Modelo da Complexidade. O pesquisador aponta que o sistema formativo do professor está estruturado nos alicerces do modelo cartesiano, com uma estrutura hierárquica, compartimentalizado e mentalista, reproduzindo o modelo de Educação tradicional. No entanto, 
para que as mudanças ocorram, deve-se modificar o pensamento, considerando uma mudança paradigmática para isso.

Já Pereira (2017) sinaliza que ainda hoje persiste a falta de articulação dos conhecimentos e que a práxis educativa com base na Complexidade pode promover uma reformulação do pensamento e preparar os professores para o desafio da sala de aula no século XXI. Acrescenta que a Educação Física nem sempre prepara o profissional para enfrentar os desafios da atuação na escola, talvez pela formação acadêmica rodeada de diversas teorias que não dialogam entre si. Por serem tantas vertentes, muitos professores talvez as desconheçam ou as compreendem parcialmente, o que corrobora com a fragmentação do conhecimento. Por essa razão, endossa que entender como as teorias implicam diretamente na forma como preparam professores para educar, deve ser tarefa central em uma licenciatura.

Encontramos relações nos estudos desenvolvidos por Wadt (2009) e Maissiat (2013). Enquanto o primeiro se ocupa em tentar oportunizar aos professores em formação melhor compreensão dos processos e ações presentes num ambiente on-line e uma tomada de atitudes mais conscientes e adequada nesse ambiente, o segundo parte do interesse de identificar quais são as ações necessárias em um ambiente virtual de ensino e de aprendizagem, para capacitar um professor a fim de que ele possa ser entendido como um sujeito complexo.

O estudo desenvolvido por Wadt (2009) observou que a atitude do professor é o ponto central de suas ações, e na proposta da pesquisa considerou que as ações pautadas na união, na contextualização, na globalização das informações e dos saberes foram o ponto de partida para a possibilidade de uma visão que contemple a Complexidade no curso on-line. No trabalho de Maissiat (2013), também foi possível observar os elementos da Complexidade presentes. Os professores demonstraram que suas atitudes e decisões, permitidas pela arquitetura pedagógica do curso, apresentassem a emergência das características do sujeito complexo como inerente à contemporaneidade, concluindo que a relação com a EaD, ambientes virtuais e Complexidade é adequada.

Ainda sobre o trabalho de Wadt (2009), a pesquisadora destaca a Complexidade como uma teoria vasta e universal e conclui que independente do lugar em que se possa estar, nunca será possível a percepção completa do todo, mas é necessário que se faça um esforço racional no sentido de conseguir olhar o possível da totalidade para que se considere o que for especialmente importante em todos os âmbitos nas ações docentes. Na mesma direção, Maissiat (2013) acrescenta que falar em Complexidade não indica simplesmente buscar respostas, mas também perceber os novos desafios que surgem. 
Os estudos de Klammer (2011) e Lopes (2015) também apresentam aproximações: ambos tratam da formação continuada. Klammer (2011) indica que a base mecanicista sustenta o fazer e o pensar do professor universitário e que sua dificuldade está em enfrentar a confusão, a incerteza, a contradição e ao mesmo tempo conviver com a solidariedade dos fenômenos existentes em si mesmos. Nessa direção, Lopes (2015) sinaliza que a Complexidade é pouco compreendida pelos docentes universitários das licenciaturas. Eles receberam uma formação inicial técnica em área especifica, verticalizada por cursos de pós-graduação stricto sensu, o que valoriza o conhecimento específico, pautada em pilares do paradigma cartesiano. Eles vivem um dilema - já que sua ação docente é pautada em pressupostos do paradigma conservador, mas são convocados a reafirmar o paradigma inovador.

No que concerne a Complexidade, Klammer (2011) vê esse paradigma como uma dimensão inovadora e diferenciada que proporciona uma revisão na visão de mundo e de ser humano. Em sua pesquisa indica que o curso investigado ainda que não tenha consolidado esta visão na prática dos professores, contribuiu para uma agitação e uma desordem no fazer e no pensar dos professores. Esta desordem levou-os a buscarem novas formas de pensar a realidade, novas ideias e novas articulações.

Sobre o estudo de Lopes (2015) a pesquisadora enfatiza a necessidade de uma prática docente em uma perspectiva integradora e acrescenta que o grande desafio para o docente universitário contemporâneo é estar preparado para formar docentes capazes de perceber a Complexidade do processo ensino-aprendizagem. Na contemporaneidade torna-se inconcebível ensinar, separando o indivíduo do ambiente em que vive e fragmentando o conteúdo a ser ensinado. Em sua pesquisa revela que foi possível materializar uma formação contínua e em serviço aos docentes universitários e a partir de atividades desenvolvidas individual e cooperativamente, os professores refletiram e reelaboraram a compreensão conceitual específica na perspectiva sistêmico-complexa.

O trabalho de Fialho (2011) indica que uma comunidade virtual e de prática, se vista na perspectiva dos sistemas complexos, ajuda-nos a entender a Complexidade não só de uma sala de aula, mas também a de ensinar e de aprender uma língua estrangeira, presencialmente ou à distância. A pesquisadora defende que apenas uma adaptação das atividades e dos materiais usados no ensino presencial não garante maior motivação, interação e autonomia entre os envolvidos na EAD e que as disciplinas à distância podem tirar proveito dos ambientes virtuais de aprendizagem e que neles os membros podem aprender de forma mais colaborativa.

Na mesma direção, Burian (2018) destaca a importância dos processos formativos mediados por tecnologias para o desenvolvimento da autonomia do professor. Sua investigação 
propicia a conscientização sobre a relevância da comunicação/interação, dos princípios e dos sistemas que possibilitam enxergar a Complexidade, além de sinalizar o potencial que os ambientes digitais de aprendizagem têm para contribuir para a Formação de Professores especialmente se pensados a partir de uma proposta complexa. Enfatiza que o oferecimento de um curso de formação baseado na Complexidade e no design educacional complexo para os professores possibilitou aos participantes o conhecimento sobre este paradigma, mesmo que a organização curricular baseada na fragmentação e compartimentalização do conhecimento ainda seja realidade em diferentes contextos educacionais, até mesmo nos cursos de Formação de Professores.

No desenvolvimento de seu trabalho Batista (2012) questiona o modelo paradigmático tradicional, mas não ignora o que a Modernidade possibilitou. Sinaliza que a Complexidade não pretende unificar todas as teorias que rejeitam e questionam os preceitos paradigmáticos do modelo mental vigente, pois ele não é mais um paradigma reducionista, mas objetiva tecerse em conjunto com essas teorias, de modo a construir teorias hídricas, ou pontes. Defende que a epistemologia da Complexidade pode ajudar a sair do pensamento mutilante, que fragmenta o conhecimento em vez de juntá-lo e indica a reforma de pensamento para que os princípios da Complexidade possam mudar as maneiras de o homem pensar, sentir e agir. Sobre as contribuições de sua pesquisa para a área de Formação de Professores, informa que foram destacadas como enormes, principalmente, porque adotam construtos epistemológicos e metodológicos inovadores e contemporâneos, que rompem com os modelos de Formação de Professores. Embora denote o alcance destas contribuições, observa a presença forte ainda do paradigma newtoniano- cartesiano, que privilegia as homogeneidades, as centralidades e a falta de diferença, bem como as parcialidades, as objetividades, as previsibilidades, as neutralidades, as linearidades e as certezas.

O estudo de D’Espósito (2012) aponta que a mudança paradigmática repercute na educação e afeta a forma como vemos a prática docente, como pensamos, como desenhamos e implementamos cursos e tarefas, bem como a formação que oferecemos aos alunos. Sua investigação indica que na sociedade contemporânea, que prioriza a multiplicidade e simultaneidade de linguagens e valoriza o conhecimento em rede, não encontra mais relação com o paradigma educacional tradicional. Sobre os resultados de sua investigação, aponta que desenvolveu o desenho e a implementação do curso complexo, à distância e que o curso pôde favorecer a pesquisadora inúmeras descobertas sobre como atuar nesse ambiente a distância.

Ao apresentar novas estratégias de formação, Priuli (2017) se propôs a que estas possam fornecer aos professores ferramentas para desenvolver vídeos educacionais que atendam às suas 
expectativas e as dos alunos. No que diz respeito a Complexidade, dá ênfase a uma visão dialógica complementar aluno/professor e invoca o olhar multifacetado, propondo um trabalho colaborativo entre profissionais do audiovisual e professores, indicando que juntos podem promover contribuições educacionais. O estudo propiciou aos futuros profissionais saberes para desenvolver uma escrita audiovisual, capaz de imprimir sentido nas obras audiovisuais educacionais e destaca que o conceito de aula deve ser revisitado em tempos de hibridização entre tecnologias, presencialidade, distâncias, e o professor, já em sua formação inicial, precisa tomar contato e se apropriar dessas questões. Sobre as formações de professores traz um alerta, principalmente para as licenciaturas que desconsidera a EAD em seus currículos: é preciso refletir sobre o processo que utiliza fragmentos capturados pela tecnologia para se constituir em uma nova linguagem, de modo que possa extrapolar as barreiras impostas pela fragmentação de saberes.

No que concerne aos objetivos que compõem as pesquisas do segundo bloco, que tomam os professores como sujeitos de investigação para tratar de sua formação, destacam-se:

a) Analisar a ação docente dos professores de Publicidade e Propaganda a luz dos referenciais teórico-práticos que subsidiam o paradigma da Complexidade (POSSOLLI, 2009);

b) Analisar a necessidade de formação continuada dos docentes que atuam na Educação Profissional com cursos de nível médio e sua predisposição para o envolvimento na educação continuada, para o desenvolvimento de um paradigma inovador na prática pedagógica no ensino técnico (CARPIM, 2011);

c) Desvelar e compreender como um grupo de docentes em engenharia da UFC se apropria de um referencial didático-pedagógico complexo na problematização e transformação de suas práticas (RABELO, 2011);

d) Investigar a formação tecnológica oportunizada pela Aula Tecnologias para o ensino de línguas na perspectiva do aluno no modulo Interação na Formação Docente de um curso de Graduação em Letras: Português/Espanhol à distância (PITOMBEIRA, 2013);

e) Ampliar a discussão sobre a formação do professor de matemática no sentido da inteireza do ser e perspectiva da teoria da Complexidade (DORNELLES, 2013);

f) Analisar se os sete saberes propostos por Morin encontram-se presentes nas concepções e nas práticas docentes dos formadores dos educadores ambientais (SAHEB, 2013);

g) Analisar a Complexidade e a dinamicidade das crenças de alunos/formandos de LetrasPortuguês e do curso de Letras-Espanhol da Universidade Estadual do Piauí - (UESPI) acerca da variação linguística (GOMES, 2014); 
h) Analisar como os docentes articulam seus saberes para discutir, compreender e explicar questões sobre processos orgânicos, na ótica da Biologia sistêmico- complexa (SOUZA,2015);

i) Descrever e interpretar os seguintes fenômenos: Auto-heteroecoformação de Professores de espanhol em um curso de licenciatura e ser professor complexo de espanhol na perspectiva de alunos da licenciatura (AGUIAR, 2016);

Nesse segundo bloco de pesquisas, observamos uma acirrada crítica em direção dos cursos de Formação de Professores. Nos estudos que investigam os professores universitários, destaca-se a falta de uma formação pedagógica e sinaliza também a falta de investimento em formação continuada por parte destes professores, embora esta seja uma função do financiamento público do Estado. Verificamos ainda que muitos estudos deste bloco focalizam a prática pedagógica dos professores.

Nos trabalhos de Possolli (2009), Carpim (2011) e Rabelo (2011) encontramos aproximações. No primeiro, a investigação focaliza a prática pedagógica de professores e coordenadores do curso de Publicidade e Propaganda e procura identificar os fatores que influenciam nessa prática. No segundo o estudo se propõe a responder como o professor que atua com a formação profissional pode mudar sua ação docente e no terceiro, as lentes se voltam para compreender como um grupo de docentes em engenharia se apropria de um referencial didático-pedagógico e transforma suas práticas. Os resultados dos três trabalhos também são muito semelhantes. No estudo desenvolvido por Possolli (2009) o estudo sinaliza carência por titulação e formação pedagógica, já que somente $25 \%$ do grupo busca formação pedagógica nos cursos de pós-graduação. Na pesquisa de Carpim (2011) os 33 professores envolvidos na investigação possuem apenas a formação técnica específica e não possuem os conhecimentos didáticos e pedagógicos. Na mesma direção, a pesquisa desenvolvida por Rabelo (2011) constata que os docentes em engenharia são formados exclusivamente para tratar das questões do mundo tecnológico e exercem suas funções sem receber uma formação que os capacitasse para lidar com as questões pedagógicas, o que caracteriza uma fragmentação.

Possolli (2009) sinaliza que apesar de a maior parte do grupo de coordenadores ter se mostrado preocupado com a formação de seus professores, alguns coordenadores não investem nem mesmo em sua própria formação. Nota-se que o grupo demonstra ser influenciado por exigências institucionais, pelo mercado de trabalho e pela falta de comprometimento de grande parte dos alunos, que veem na Universidade o espaço para conquistar uma vaga no mercado de trabalho e não um momento para reflexão, crítica e pesquisa. Na pesquisa de Carpim (2011), 
somente $10 \%$ dos professores se mostraram receptivos e dispostos a participar do Curso de Formação Continuada.

Sobre a Complexidade, Possolli (2009) indica que o paradigma ganha relevância, pois acolhe uma nova visão que exige pensamento complexo, reflexivo, crítico e transformador e que o grupo pesquisado demonstrou um claro esforço pela superação da visão conservadora na busca por paradigmas inovadores. Carpim (2011) indica que embora os professores investigados tenham sido formados atendendo aos paradigmas tradicionais de ensino, com os pressupostos reducionistas e cartesianos, estão receptivos quanto a mudar suas práticas, visto que o paradigma da Complexidade nos oferece uma nova forma de ser, de conviver e de entender o mundo, para melhor viver.

A Complexidade é compreendida por Rabelo (2011) como uma nova racionalidade, que envolve uma grande diversidade de conceitos que toma emprestado a autores pertencentes a diversos campos do saber. É uma busca do pensar bem. No estudo deste autor, a Complexidade aparece aos docentes em duas vertentes: como desafios do mundo contemporâneo e como as qualificações e competências que a educação deve suprir.

Quanto a investigação desenvolvida por Saheb (2013), a preocupação em torno da prática pedagógica também se apresenta. Com o objetivo de analisar se os sete saberes propostos por E. Morin encontram-se presentes nas concepções e nas práticas docentes dos formadores dos educadores ambientais, os resultados revelaram que estes saberes se constituem como uma importante contribuição epistemológica e metodológica para a formação de educadores ambientais e ainda que, de forma embrionária, encontram-se presentes em ambos os processos de formação. Entretanto uma dificuldade constatada foi a transposição do paradigma da Complexidade na para a prática pedagógica, pelo fator de a tradição de um pensamento de disjunção presente em nossa cultura ser apontada pelos professores como predominante na Universidade, tanto por parte da estrutura quanto pelos seus pares. No entanto acredita-se que a abertura ao diálogo com os fundamentos científicos e filosóficos convergentes com a Complexidade demonstrada pelos professores entrevistados, pode ser vista como um elemento importante no caminho para a transformação rumo à construção do pensamento complexo.

Souza (2015) se ocupou em compreender as interações desenvolvidas nas discussões, identificar os saberes mobilizados e as concepções paradigmáticas que se revelariam nas postagens de um grupo de docentes no Facebook. Os resultados apontaram que o grupo de estudos no Facebook representou uma possibilidade palpável para a Formação de Professores, pois os docentes desenvolveram suas atividades discursivas, muito ligadas às suas áreas de 
atuação. Mas isso não implica dizer que os demais olhares não abriram perspectivas novas de conhecimento de mundo, sendo que a pesquisa aponta que ter atitudes e pensamentos com uma nova perspectiva não é fácil nem cômodo, principalmente com a forma rígida de formação, inclusive a continuada - que embora assuma o discurso de implementação de perspectivas inovadoras, assume muitas vezes uma prática condizente com o tradicional.

Na pesquisa de Dorneles (2013), a compreensão sobre o desenvolvimento das dimensões subjetivas na formação do professor de Matemática foi o foco. Segundo a pesquisadora, a Matemática no Brasil é um curso que se apresenta tensionado entre a herança do pensamento linear e cartesiano e a emergência de outros paradigmas que olham o ser humano e o mundo de maneira integral.

A compreensão obtida pela interpretação dos achados de Dorneles (2013) apontou que os entrevistados reconhecem a presença das dimensões racional, social e até a emocional, porém veem com reserva, a dimensão espiritual, ainda que a reconhecendo como constituinte da interioridade de cada pessoa. Perceberam a necessidade de inovar nessa formação como uma das possíveis saídas para a superação ou minimização do fracasso no ensino da Matemática e identificaram na educação continuada uma possibilidade de completude do ser humano em permanente vir a ser. Sobre alguns indicadores que podem contribuir para um repensar sobre a formação do professor de Matemática destacou-se a ampliação do diálogo do educador com seus pares. Este diálogo visaria romper a fronteira do isolamento científico, o desenvolvimento de trabalho nas interfaces das outras ciências, desenvolver propostas inovadoras de ensino em que seja possível contemplar a presença das dimensões subjetivas do ser humano, priorizar estratégias de ensino, voltadas para intervenções na realidade complexa da vida, que despertem a curiosidade, a criatividade e que permitam ao educando da matemática ter sucesso na aprendizagem e ser feliz. A ampliação da consciência do futuro professor possivelmente aconteça com o desenvolvimento das dimensões subjetivas no âmbito social, emocional e espiritual, no sentido da inteireza do ser na perspectiva da Complexidade.

Gomes (2014) indica que a este paradigma lida com comportamentos não previsíveis, aparentemente aleatórios, rompendo com a relação de causa/efeito proposta pelo paradigma positivista. Aponta que a Complexidade se originou na confluência de várias áreas, rompendo com as barreiras que distanciavam os diversos campos da ciência. Em sua investigação teve como objetivo analisar a Complexidade e a dinamicidade das crenças de alunos/formandos na área de Letras. Utilizou diferentes instrumentos de coleta de dados, mas ainda assim sinaliza que não conseguiu revelar todas as crenças dos alunos uma vez que elas possuem natureza intrincada, dinâmica e sistêmica e do ponto de vista sociolinguístico, as crenças dos graduandos 
possuem algumas possíveis implicações para a prática de ensino desses futuros professores de língua materna e estrangeira. Acrescenta que professores são apegados as concepções (crenças) restritas de língua/linguagem, o que constitui uma fragmentação do pensamento, e os docentes de língua materna não estão preparados para trabalhar com todo um conjunto de teorias e práticas que reconhecem e valorizem a heterogeneidade linguística. No ambiente universitário, espaço de Formação de Professores, muitos alunos (futuros professores) são orientados a conceber a linguagem somente como objeto de análise linguística.

A investigação de Pitombeira (2013) permitiu identificar a formação tecnológica que o aluno percebe no curso e os traços da Complexidade que poderia utilizar em outras ofertas de cursos. O estudo propiciou à pesquisadora a certeza de que uma vez tendo contato com este paradigma, algumas características se alterariam na docência e no desenho dos cursos. $\mathrm{O}$ questionário proposto no estudo propiciou uma descrição e interpretação do fenômeno e os temas desvendados sob uma perspectiva complexa e auxiliaram na revelação da realidade desse fenômeno, que certamente não poderia ser observado pelo paradigma cartesiano. Na interlocução entre Complexidade e abordagem hermenêutico-fenomenológica foi possível verificar as relações todo e partes, foram observados traços dos operadores dialógico, recursivo e hologramático de E. Morin em algumas atividades desenhadas para o curso, e os alunos compreenderam que a tecnologia por si só não tem sentido e sua utilização de modo adequado e consciente é o que levará ao conhecimento. Sobre a Complexidade, aponta como visão de mundo e o prisma que nos permite olhar, pensar e tentar compreender a construção do conhecimento. É um olhar diferenciado, não linear, não fragmentado, não compartimentado ou redutor, um olhar concomitantemente repleto de incertezas e dúvidas diante da impossibilidade do saber total e repleto da multidimensionalidade da realidade.

A pesquisa de Aguiar (2016) se propõe a repensar as ações pedagógicas, tendo em vista as ações religadas, tecidas em conjunto. A interpretação dos textos produzidos durante a investigação revela temas como desafio, exploração, reforma, conexões e que destacam a importância de uma nova abordagem no processo de formação docente, no estágio, em um curso de Letras, que conteste os paradigmas da formação tradicional de professores de língua estrangeira e que possa servir como reflexão para outros processos de formação docente, muitas das vezes distantes da realidade social e humana dos alunos. Vê a Complexidade como uma relação antagônica e complementar, que pretende contestar o formato tradicional de ensino. Aponta que Complexidade contraria o pensamento cartesiano que tem como base a distinção e clareza como características, não sendo hermética, conclusiva e determinista. 


\section{CONSIDERAÇÕES FINAIS}

Este trabalho apresenta um estado da arte de dissertações e teses desenvolvidas entre os anos de 2000 a 2018 com foco na Formação de Professores sob a perspectiva da Complexidade. Os resultados da análise indicam que essa perspectiva aparece nas modalidades presenciais e a distância e em diferentes de níveis de ensino tais como nos anos finais do Ensino Fundamental, no Ensino Médio, no Ensino Superior, na Pós-Graduação em nível de Especialização e nas dimensões tecnológica e profissional, revelando que há estudos já consolidados sobre o tema. Observamos a forte presença da EAD e do uso dos Ambientes Virtuais de Aprendizagem nos estudos analisados, bem com a presença dos vários trabalhos que vinculam a Complexidade e os estudos de línguas estrangeiras.

Esta transversalidade é possibilitada pelos princípios apontados pelo paradigma da Complexidade que, como exposto em 'Os sete saberes necessários à educação do futuro' (Morin, 2000), no qual não se explicitam temáticas ou programas específicos a nenhum tempo educativo, mas pressupostos fundamentais para a construção de um conhecimento experienciado em repensares coletivos para constituição de uma sociedade que valorize a condição humana.

Sobre os contextos nos quais estes trabalhos foram desenvolvidos, destacam-se as universidades privadas, sobretudo na região Sudeste, seguida da região Sul, regiões brasileiras que concentram o maior número de programas e de cursos de pós-graduação do país. Este recorte da formação continuada na Pós-graduação aponta a dificuldade de inserção dos preceitos do paradigma da Complexidade nos cursos de formação inicial pelos cursos de graduação. Nestes espaços formativos, encontra-se maior rigidez quanto ao desenvolvimento do conhecimento científico ainda impregnado por paradigmas de controle da ciência - que se pautam pelas ilusões da certeza que padroniza problemas epistemológicos, filosóficos e éticos (Morin, 2000).

Ao buscarmos identificar o que as produções acadêmicas sinalizam sobre a Complexidade e a Formação de Professores, observamos uma acirrada crítica aos modelos de formação que se alicerçam em paradigmas da Era Moderna em um consenso de que tais modelos não dialogam mais com as demandas que a atualidade impõe e repensar a formação do professor é necessária e urgente. Este consenso vai de encontro às prescrições apresentadas por E. Morin (2014) quanto à capacidade de organizar e produzir conhecimentos para uma reforma do pensamento, em uma construção de situar princípios organizadores que conectem os saberes. Embora o autor afirme que esta aptidão é inerente aos seres humanos, a mediação 
dos processos educativos e seus agentes centrais - os professores, é que podem aprimorar o exercício da curiosidade e a formulação de questionamentos que confiram sentidos e identifiquem conexões para solucionar problemas especiais e complexos. Os resultados desta pesquisa apontam que o caminho é longo, mas o percurso já foi iniciado.

\section{REFERÊNCIAS}

AGUILAR, Gabriel Jimenez. A auto-heteroecoformação de alunos-professores de um curso de Letras em espanhol: reconstruindo significados da docência em uma perspectiva complexa. 2016. 221 f. Tese (Doutorado em Linguística Aplicada e Estudos da Linguagem) - Pontifícia Universidade Católica de São Paulo, São Paulo, 2016.

BATISTA, Luís Otavio. Tecendo teias complexas em curso online para futuros professores de inglês. 2012. 269 f. Tese (Doutorado em Linguística Aplicada e Estudos da Linguagem) Pontifícia Universidade Católica de São Paulo, São Paulo, 2012.

BEHRENS, Marilda Aparecida. Paradigma da Complexidade. Metodologia de projetos, contratos didáticos e portfólios. 3 ed. Petrópolis: vozes, 2011.

BURIAN, Eliana Aparecida Oliveira. Formação online de professores de inglês dos anos finais do ensino fundamental da rede pública do Estado de São Paulo, sob a perspectiva da Complexidade. 2018. 173 f. Tese (Doutorado em Linguística Aplicada e Estudos da Linguagem) - Pontifícia Universidade Católica de São Paulo, São Paulo, 2018

CARPIM, Lucymara. Formação pedagógica dos professores do ensino técnico: caminhos históricos para um paradigma da Complexidade. 2011. 173 f. Dissertação (Mestrado em Educação) - Pontifícia Universidade Católica do Paraná, Curitiba, 2011.

D'ESPOSITO, Maria Eugenia Witzler. Prática escrita em língua inglesa: um curso online para professores da rede estadual, sob a perspectiva da Complexidade. 2012. 344 f. Tese (Doutorado em Linguística Aplicada e Estudos da Linguagem) - Pontifícia Universidade Católica de São Paulo, São Paulo, 2012.

DORNELLES, Mara Iara da Costa. Contribuições a uma proposta de formação de inteireza do professor de matemática na perspectiva da Complexidade. 2013. $144 \mathrm{f}$. Tese (Doutorado em Educação) - Pontifícia Universidade Católica do Rio Grande do Sul, Porto Alegre, 2013.

FIALHO, Vanessa Ribas. Comunidades virtuais na Formação de Professores de espanhol língua estrangeira a distância na perspectiva da Complexidade. 2011. 204 f. Tese (Doutorado em Letras) - Universidade Católica de Pelotas, Pelotas, 2011.

GOMES, Yana Liss Soares. As crenças de formandos de português e de espanhol acerca da variação linguística: um estudo na perspectiva da Complexidade. 2014. $171 \mathrm{f}$. Tese (Doutorado em Linguística Aplicada) - Universidade Federal de Minas Gerais, Belo Horizonte, 2014

KLAMMER, Celso Rogerio. Formação continuada para a prática docente no paradigma da Complexidade com uso das tecnologias da informação e comunicação. 2011. 303 f. Tese (Doutorado em Educação) - Pontifícia Universidade Católica do Paraná, Curitiba, 2011. 
LOPES, Fernanda Muniz Brayner. Formação de docentes universitários: um complexo de interações paradigmáticas. 2015. 259 f. Tese (Doutorado em Ensino das Ciências) Universidade Federal Rural de Pernambuco, Recife, 2015.

MAISSIAT, Jaqueline. Interconexões entre a Complexidade e o fazer docente: formação continuada e tecnologias digitais em educação a distância. 2013. 180 f. Tese (Doutorado em Informática Educação) - Centro Interdisciplinar de Novas Tecnologias na Educação, Universidade Federal do Rio Grande do Sul, Porto Alegre, 2013.

MALOSSO FILHO, Marcolino. A educação e a teoria da Complexidade na Formação de Professores: problemas e desafios. 2012. 132 f. Tese (Doutorado em Educação) - Programa de Educação Escolar da Faculdade de Ciências e Letras, Universidade Estadual Paulista, Araraquara, São Paulo, 2012.

MORIN, Edgar. Os sete saberes necessários à educação do futuro. Tradução de Catarina Eleonora F. da Silva e Jeanne Sawaya. Revisão técnica de Edgard de Assis Carvalho. 2. ed., São Paulo: Cortez; Brasília, DF: UNESCO, 2000.

MORIN, Edgar. A cabeça bem-feita: repensar a reforma, reformar o pensamento. Rio de Janeiro: Bertrand Brasil, 2014.

PEREIRA, Dimitri Wuo. O pensamento complexo de Edgar Morin: subsídios teóricos para a superação da fragmentada formação do professor de educação física. 2017. 152 f. Tese (Doutorado em Educação) - Universidade Nove de Julho, São Paulo, 2017.

PITOMBEIRA, Cátia Veneziano. Caminhos da formação tecnológica a distância: a Complexidade emergente no desenho de curso de licenciatura. 2013. Tese (Doutorado em Linguística Aplicada e Estudos da Linguagem) - Pontifícia Universidade Católica de São Paulo, São Paulo, 2013.

POSSOLI, André Hildo Eyng. A prática pedagógica dos docentes do curso de publicidade e propaganda a luz do paradigma da Complexidade. 2009. 149 f. Dissertação (Mestrado em Educação) - Pontifícia Universidade Católica do Paraná, Curitiba, 2009.

PRIULI, Ricardo Medeiros. Uma aula na cabeça, uma câmera na mão: a transposição para vídeo aula na Formação de Professores na perspectiva da Complexidade. 2017. 163 f. Dissertação (Mestrado em Linguística Aplicada e Estudos da Linguagem) - Pontifícia Universidade Católica de São Paulo, São Paulo, 2017.

RABELO, João José Evangelista. Docência em engenharia: uma experiência de formação a partir do pensamento complexo. 2011. 291 f. Tese (Doutorado em Educação) - Pontifícia Universidade Católica de São Paulo, São Paulo, 2011.

ROMANOWSKI, Joana Paulin; ENS, Romilda Teodora. As pesquisas denominadas do tipo "estado da arte" em educação. Revista Diálogo Educacional, Curitiba, PUC/PR, v. 6, n. 19, p. 37-50, set./dez. 2006.

SAHEB, Daniele. Os saberes socioambientais necessários à educação do presente e a formação do educador ambiental sob o foco da Complexidade. 2013. $218 \mathrm{f}$. Tese (Doutorado em Educação) - Universidade Federal do Paraná, Curitiba, 2013 
SOUZA, Aline Furtuozo de. Relações discursivas na compreensão de processos biológicos sistêmico-complexos em uma rede social: contribuições para a formação do docente universitário. 2015. 190 f. Dissertação (Mestrado em Ensino das Ciências) - Universidade Federal Rural de Pernambuco, Recife, 2015.

WADT, Maria Paula Salvador. Complexidade e auto-eco-Organização: implicações para o professor on-line. 2009. 281 f. Tese (Doutorado em Linguística Aplicada e Estudos da Linguagem) - Pontifícia Universidade Católica de São Paulo, São Paulo, 2009.

\section{SOBRE AS AUTORAS}

Priscila Moreira Silva de Farias é mestre em Educação pela Universidade Federal de São Carlos (UFSCar), graduada em Pedagogia e Administração Escolar, com as seguintes especializações: Psicopedagogia Clínica e Institucional pela PUC-SP; Educação Infantil, em Práticas de Alfabetização e Letramento; Planejamento, Implementação e Gestão da Educação à Distância. Atualmente atua na coordenação de Polo de Apoio Presencial na Rede UniCEU/UAB.

E-mail: priscilamoreiradefarias@gmail.com

ORCID: https://orcid.org/0000-0001-6307-868X

Rosa Aparecida Pinheiro é doutora em Educação pela Universidade Federal do Rio Grande do Norte (UFRN), com Estágio Doutoral na Universidad de Barcelona, e Pós-doutorado na Universidade do Estado do Rio de Janeiro (UERJ). Tem Mestrado em Educação pela Universidade Federal da Paraíba e Licenciatura em Pedagogia pela Universidade Federal de São Carlos (UFSCar). É professora da UFSCar, campus Sorocaba, atuante no curso de graduação em Pedagogia e na Pós-graduação em Educação. É Coordenadora Acadêmica do Programa Residência Pedagógica e Integrante do GT 18 EJA - ANPED.

E-mail: rosapinheiro@ufscar.br

ORCID: https://orcid.org/0000-0002-4910-4842 